\title{
Subglandular mammary augmentation with aqua dissection
}

\author{
Kyungwon Park, MD, PhD \\ Kkumizia Plastic Clinic, Seoul, Rep. of Korea
}

\begin{abstract}
Background: The traditional transaxillary approach of submuscular implant breast augmentation is accompanied by severe pain, heavy bleeding, and many side effects. This subglandular mammary augmentation with aqua dissection (SMAAD) is developed for cover above problems.

Objective: Surgery with little bleeding is characterized by mild pain, minor side effects, and a short operating time.

Methods: The main accomplishment of sub-glandular mammary augmentation accompanied by aqua dissection and the finger dissection without use of instruments through a half incision of the subareolar area pre-treated by the Klein solution (Aqua-dissection), which is the main technique used to minimize bleeding. An injection of $250 \mathrm{ml}$ of Klein solution was inserted in each breast before incision and the finger-only technique was used for pocket dissection. A 200 to $350 \mathrm{ml}$ textured cohesive gel implant was inserted. The drain-keep time was 2 to 7 days.

Results: Among the 600 operational patients, only 7 cases underwent capsular contracture and 4 cases experienced hematoma. An average operation time was short (about 40 minutes). This caused by short pocket dissection help of aqua dissection. The merits of SMAAD are numerous (a low rate of capsular contraction and short time operation and normal life was possible just after operation), which indicates why it could be said that an epochal method of implant breast augmentation.

Conclusion: This study was performed to evaluate the results of 600 cases of SMAAD. And indicates why SMAAD is a simple, less painful, and less side-effect-inducing surgical technique.
\end{abstract}

Keywords: aqua-dissection; finger dissection; Klein solution

\section{Introduction}

Breast augmentation surgery is a pocket-making procedure. The Pocket-making process is important; during this process there is usually a copious amount of bleeding. If there is way to make it easier with less breeding, a simple surgery would occur. The above reason indicating subglandular mammary augmentation with aqua dissection (SMAAD) has very important meaning. Before pocket dissection for implant, this SMAAD method use Klein solution. Together with expansion effect of water, can- nula dissection effect, and epinephrine effect, the pocket making process could be done very easily and with less blood loss. That's why complication after augmentation is decreased.

\section{Materials and methods}

From 2002 to 2007, 600 cases of implant breast augmentation have been performed via the SMAAD method. In intravenous anesthesia, needle puncture was performed in an inframammary crease and $250 \mathrm{ml}$ Klein solution were infused to the ret-

Received February 5, 2018; Revised May 16, 2018; Accepted May 21, 2018

Corresponding author: Kyungwon Park

E-mail: gobby1@nate.com, ORCID: https://orcid.org/0000-0001-9483-8047

This is an Open Access article distributed under the terms of the Creative Commons Attribution Non-Commercial License (http://creativecommons.org/licenses/by-nc/4.0), which permits unrestricted non-commercial use, distribution, and reproduction in any medium, provided the original work is properly cited.

Copyright @ 2018 Korean Society of Korean Cosmetic Surgery and Medicine (KSKCS \& KCCS). 
romammary fatty layer at each breast with a 15-gauge cannula (Fig. 1 [1]). After sufficient cannula dissection, a periareolar half incision was performed by using a 15-number mes (Fig. 2 [1]). Direct incision was performed by number 10 mes to retromammary fatty layer. Subsequently, a finger was only used for pocket dissection (Fig. 3 [1]). Cohesive gel implant was inserted (Fig. 4 [1]). The drain was inserted for approximately 2 to 7 days (Fig. 5 [1]). A stitch-out was completed on postoperative day 14 . Follow-up was performed at 1 month, 3 months, 6 months, 1 year, and 2 years postoperatively to observe observations.

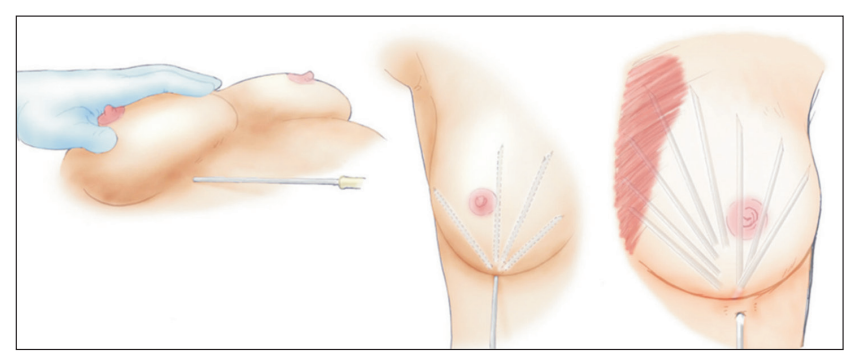

Fig. 1. Klein solution insertion. Cited from the book of Park KW. (Seoul: MD World; 2010. p. 46-119.) [1].

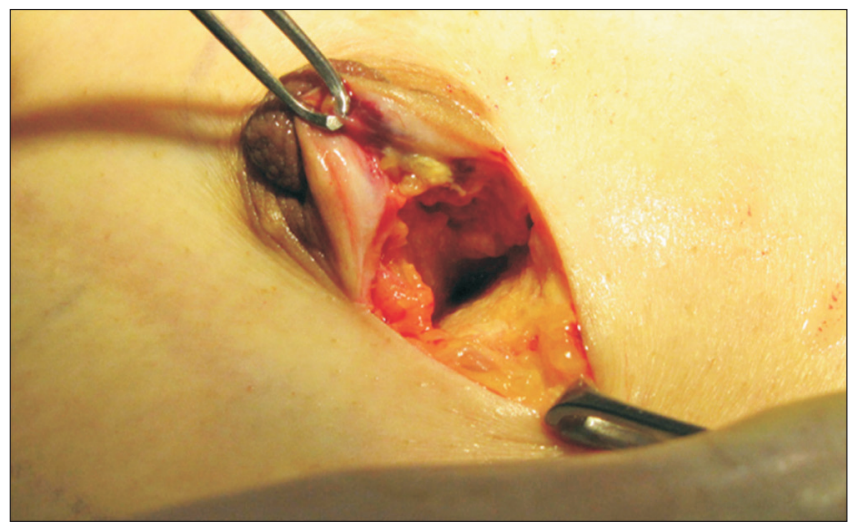

Fig. 2. Periareolar incision. Cited from the book of Park KW. (Seoul: MD World; 2010. p. 46-119.) [1].

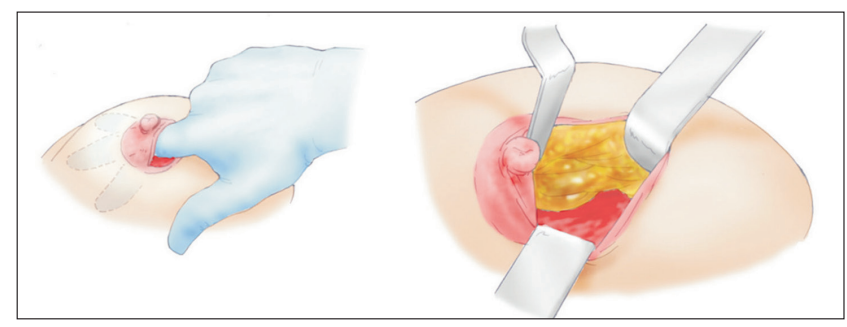

Fig. 3. Finger dissection. Cited from the book of Park KW. (Seoul: MD World; 2010. p. 46-119.) [1].

\section{Results}

After 600 cases of operation, complication was developed as below Table 1.

Capsular contraction rate was $1.167 \%$. This is an extremely low rate compared to other results. This may be caused by using texture implant and less bleeding via the SMAAD technique. Overall, the complication rate is also very low.

Fig. 6 [1] shows a reoperation case that was completed via an axillary approach 10 years ago and was re-operated via the SMAAD method. After operation, photos appear more natural than before.

Fig. 7 [1] shows skinny patient who has very small breasts with thin skin and a long nipple-to-nipple distance $(18 \mathrm{~cm})$. This qualifies a difficult implant breast augmentation; however, the results was good and the patient was very satisfied.

Fig. 8 [1] shows 3 cases of breast augmentation via the

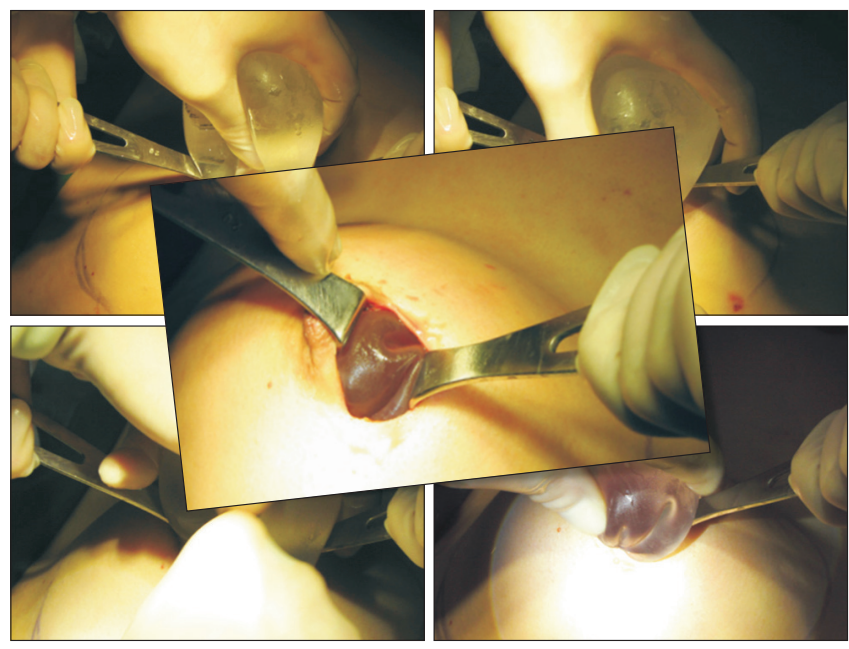

Fig. 4. Implant insertion. Cited from the book of Park KW. (Seoul: MD World; 2010. p. 46-119.) [1].

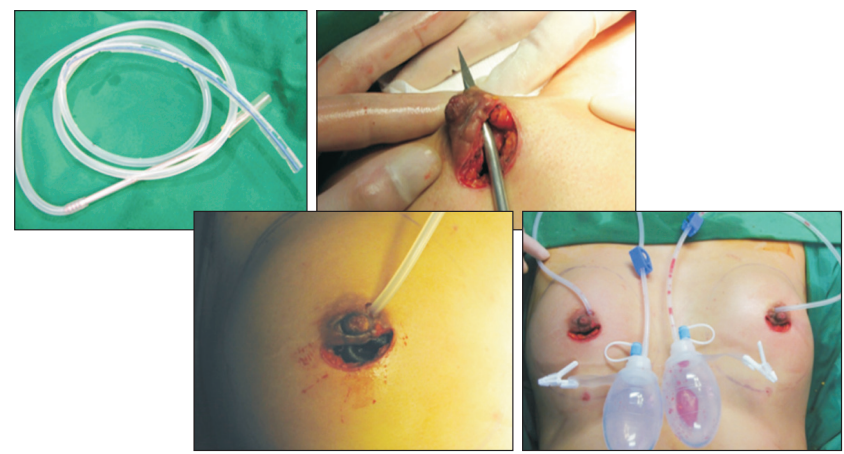

Fig. 5. Drain insertion. Cited from the book of Park KW. (Seoul: MD World; 2010. p. 46-119.) [1]. 
Table 1. Complication rates

\begin{tabular}{|lc|}
\hline \multicolumn{1}{|c}{ Symptom } & Case (\%) \\
\hline Hematoma & $4(0.667)$ \\
\hline Infection & $8(1.333)$ \\
\hline Capsular contracture & $7(1.167)$ \\
\hline Rippling & $5(0.833)$ \\
\hline Sensory loss & $3(0.500)$ \\
\hline Seroma & $1(0.167)$ \\
\hline Mondor's disease & $3(0.500)$ \\
\hline Galactorrhea & $11(1.833)$ \\
\hline Implant rupture & $1(0.167)$ \\
\hline Breast feeding difficulty & $0(0)$ \\
\hline
\end{tabular}

Values are presented as $\mathrm{n}(\%)$.
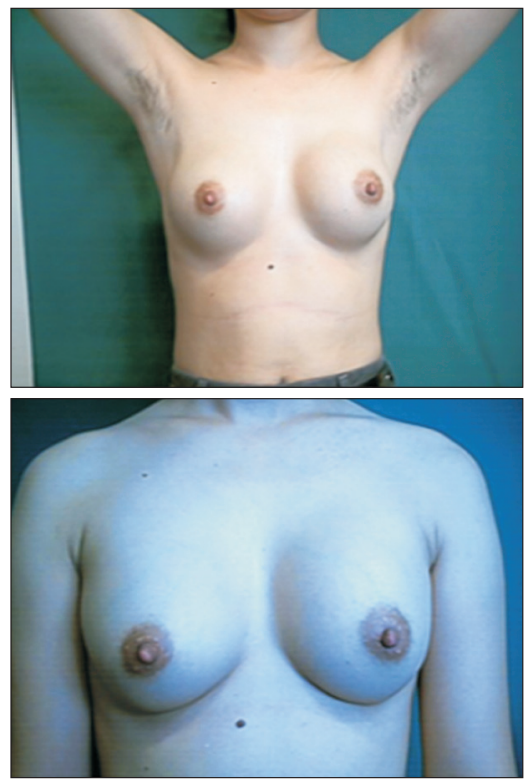

Fig. 6. Before and after photos. Cited from the book of Park KW. (Seoul: MD World; 2010. p. 46-119.) [1].
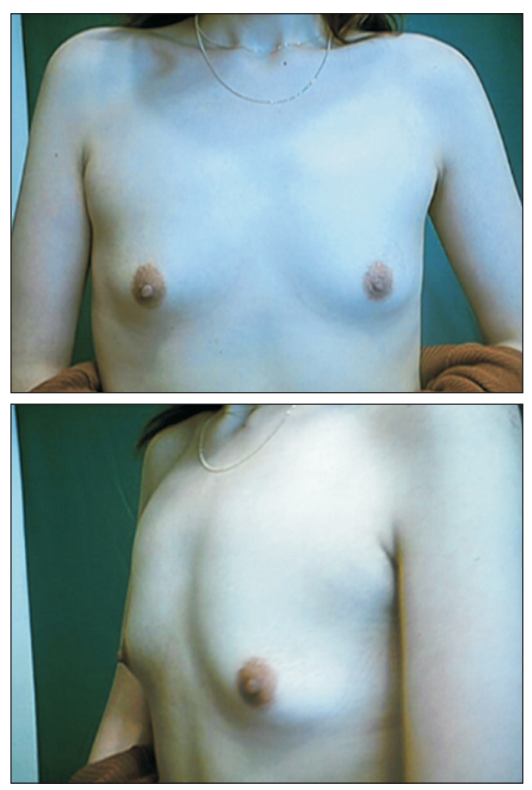

SMAAD method.

\section{Discussion}

The most common headache of breast surgeons is the high complication rate, especially in the terms of capsular contracture. The reported capsular contracture rate was from $1 \%$ to $40 \%$ as indicated below: The capsular contracture rate for dow corning company review which used Dacron patch implant was $40 \%$, for FDI review of Tebbetts [2] was $9 \%$, for aesthetic breast surgery written by Lee [3] was $3 \%$ to $10 \%$, for Shestak [4] was $15 \%$ to $20 \%$, and Bricout [5] was $15 \%$ to $20 \%$. Compared to the
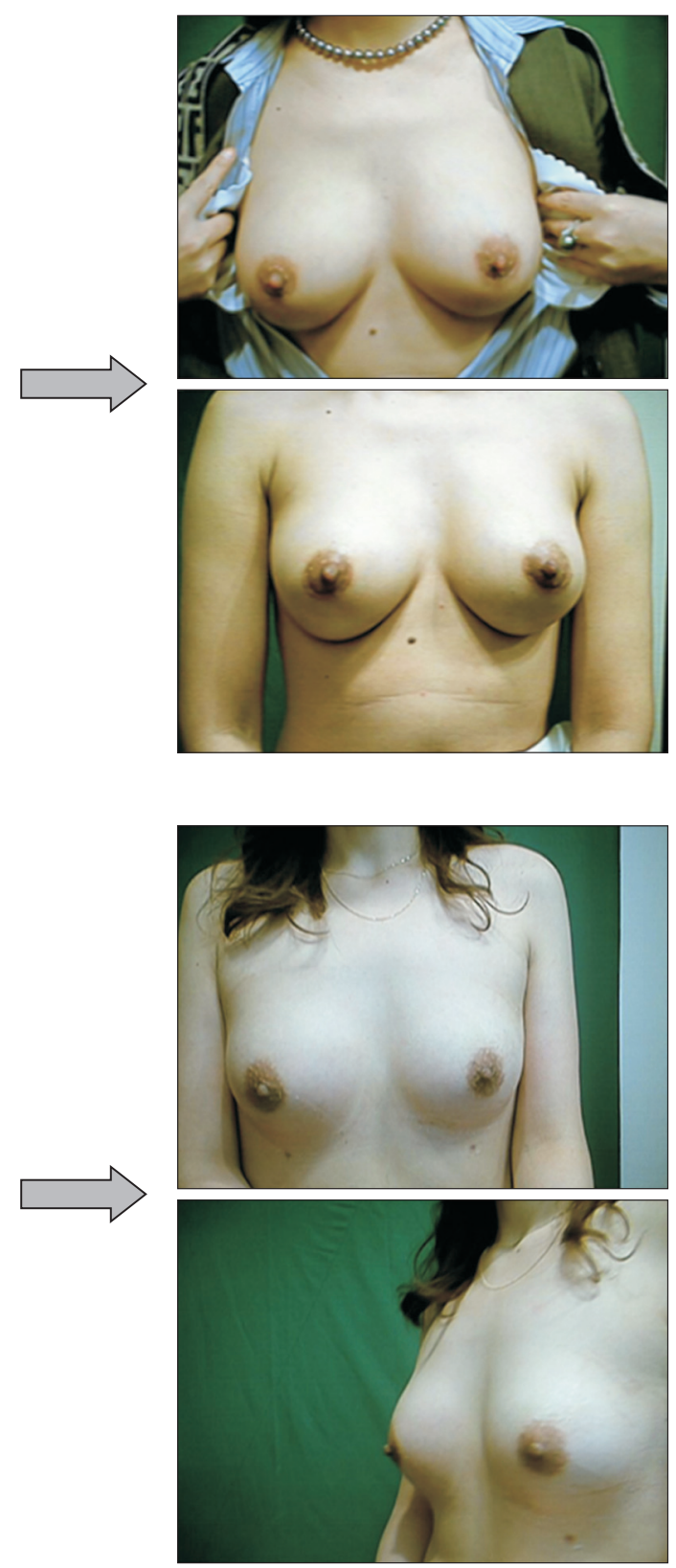

Fig. 7. Before and after photos. Cited from the book of Park KW. (Seoul: MD World; 2010. p. 46-119.) [1]. 

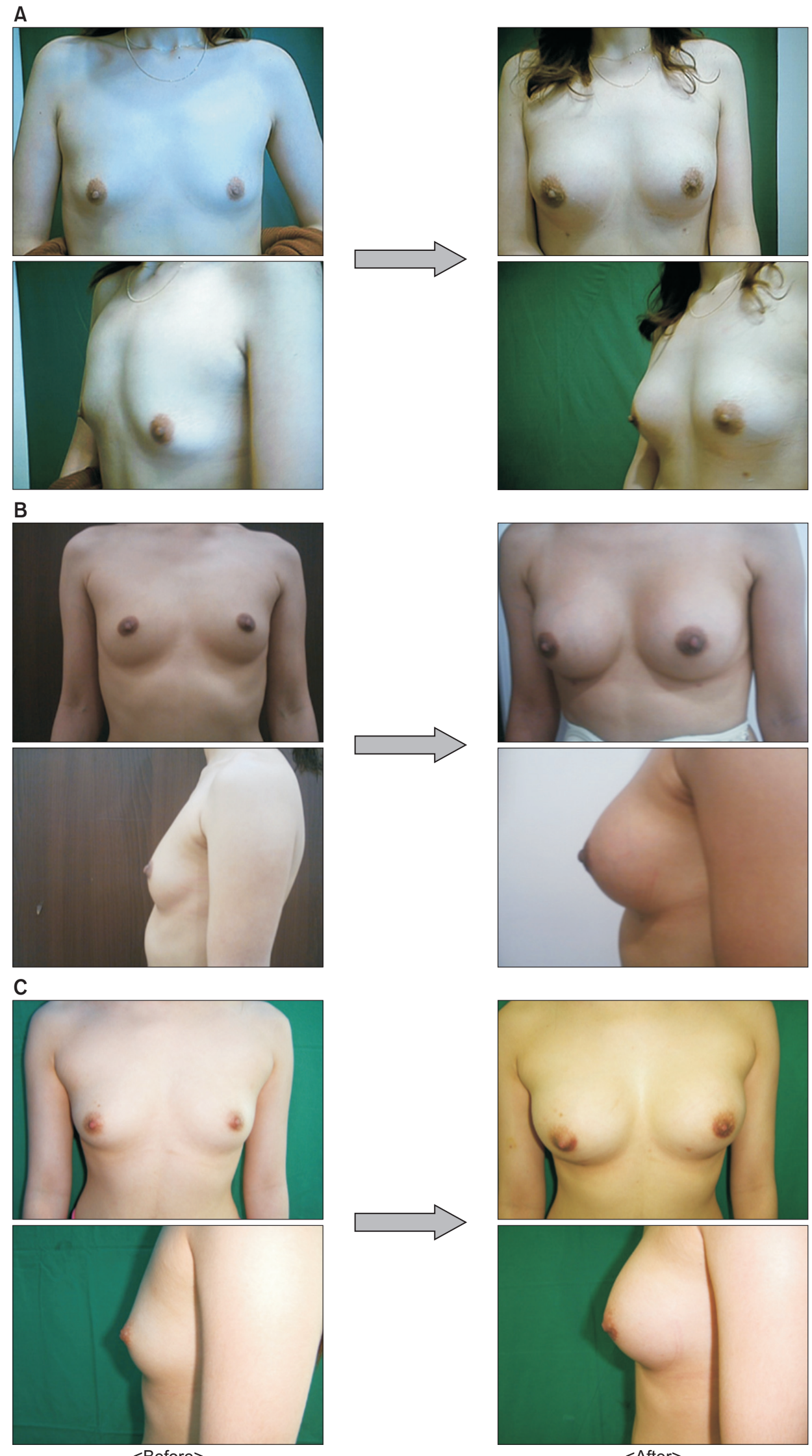

Fig. 8. Before and after photos. Cited from the book of Park KW. (Seoul: MD

<Before>

$<$ After> World; 2010. p. 46-119.) [1]. 
above report, SMAAD had a very low rate of capsular contracture at $1.167 \%$.

Put together by complication rate, operation time, satisfactory rate, and technique, this SMAAD indicates a simplified new breast augmentation process.

\section{Conflicts of interest}

The author has nothing to disclose.

\section{References}

1. Park KW. Augmentation mammoplasty. In: Park KW, editor. Breast surgery. Seoul: MD World; 2010. p. 46-119.

2. Tebbetts JB. Augmentation mammaplasty: redefining the patient and surgeon experience. Philadelphia, PA: Elsevier Health Sciences; 2009.

3. Lee JG. Insight of the aesthetic breast augmentation. Seoul: MD World; 2010

4. Shestak KC. Reoperative plastic surgery of the breast. Philadelphia, PA: Lippincott Williams \& Wilkins; 2006.

5. Bricout N. Breast surgery. Gewerbestrasse, Switzerland: Springer; 1996. 